Investigating the mediating role of cultural intelligence on the relationship between relational governance and firm social performance

Awan, Usama $\measuredangle$

Lappeenranta University of Technology Lappeenranta, Finland (usama.awan@lut.fi)

Kraslawski, Andrzej

Lappeenranta University of Technology Lappeenranta, Finland (Andrzej.Kraslawski@lut.fi)

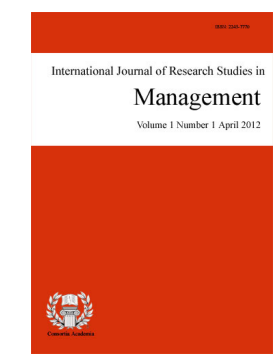

ISSN: $2243-7770$ Online ISSN: 2243-7789

OPEN ACCESS

\title{
Abstract
}

The purpose of this research is to examine mediation relationship of cultural intelligence between the relational mechanism and firm social performance. This study based on a cross-sectional survey; data were collected using self-administered structured questionnaire from the senior managers working in manufacturing firms in the Pakistan. Structural equation modelling method was used to test confirmatory factor analysis, and mediation analysis was conducted with regression analysis using SPSS macro developed by Preacher and Hayes. This study demonstrates that cultural intelligence is a critical factor for joint planning and problem solving which promotes firm social performance. We found that individual with CQ tends to have cooperative norms and enable them to overcome hurdles in joint planning and perform well in resolving conflicts through investing more cognitive efforts. Cultural intelligence is aimed at facilitating relational governance to enhance joint planning and problem solving, involves a collaborative process to improve effectiveness and communication. Thus, CQ maintains more stable inter-firm relationship, help to acquire more knowledge on social issues, ultimately achieving more socially sustainable outcomes. Empirical findings suggest that cultural intelligence warrant consideration in developing successful social sustainable performance.

Keywords: mediation analysis; cultural intelligence; social performance; cultural training 


\section{Investigating the mediating role of cultural intelligence on the relationship between relational governance and firm social performance}

\section{Introduction}

The rapid pace of globalization, increasingly inter-connected world, managers have to interact with their counterparts form different national cultures (Chandan ,2015). Specifically, export manufacturers have to work with different cultural background individuals, to be more effective in adapting to those cultural differences, a mutual understanding of business partner's culture and one's home culture is crucial. Intercultural difference can lead to misunderstanding and have a negative impact on the firm effectiveness (Cai, Yang, \& Hu, 2009). Given the importance of increased interconnectedness in global business transactions, scholars have argued that a key factor that can determine the quality of the relationships firms have with foreign partner is the supplier cultural knowledge and skills (Charoensukmongkol, 2015). Scholars have argued that firm ability to develop quality of relationship is a major factor that contributes significantly to firm performance (Moon, 2010). There is growing interest of researchers to study how supplier development lead to improve the social performance (Klassen \& Vereecke, 2012).

Cultural intelligence was introduced to the literature by Earley (2002) as "a person's capability to adapt effectively to a new cultural context." CQ is a cognitive, motivational, and behavioral skill set that allows individuals to make sense of the complexity in culture-related issues, to predict the behaviors of people from other cultures, and to adapt seamlessly to various foreign settings (Earley, 2002; Earley \& Ang, 2003). The success of collaboration is depends on the ability of the partner to create appropriate relationships. One way that firm increase this, by collaborating their partners across cultural. Recent studies, however suggest that there exist informal relationship which enhance the cooperation and collaboration among the partners (Lumineau \& Henderson, 2012). Most particularly, since informal relationship governance, which comprises of collaboration, which we maintained that joint planning, collaborative communication and joint problem solving are the most important elements of informal relationship mechanism among the buyer supplier relationship? However, to cope with the geographically dispersed partners, requires an improved understanding on how an individual capacity weigh the importance of information exchange, adaptability to develop and maintain successful relationship (Ang \& Inkpen, 2008). Developing a more holistic view of effective relationship management, Thomas, Liao, Aycan, Cerdin, Pekerti, Ravlin, et al. (2015) proposed individual with high cultural intelligence can react effectively to the demands of different cultural background partners.

Previous research studies have shown that $\mathrm{CQ}$, is an effective cultural capability for the effectiveness of individuals in cross-cultural interaction, decision making and performance (Chen, Liu, \& Portnoy, 2012). Previous studies have shown that national culture norms impacts on decision making styles and handling for differences that create challenges in terms of conflict management and communication (Gunkel, Schlaegel, \& Taras, 2016). Thus, little is known about the relative importance of skills, capabilities necessary to manage sucuess and lead in sucessful management of informal relationship. Furthermore, prior empirical studies have examined the unique contribution of culturea intelligence in supply chain perforamnce(Tuan, 2016); cultural intelligence in marketing adaptations (Magnusson, Westjohn, Semenov, Randrianasolo, \& Zdravkovic, 2013); cultural intelligence and leadership (Keung, 2011); cultural intelligence and collaboration in global teams (Janssens \& Brett, 2006); CQ and dynamic capabilities (Moon, 2010); Cutlural intelligence and team performamce (Groves \& Feyerherm, 2011); task performance (Duff, Tahbaz, \& Chan, 2012); global business competencies (Creque \& Gooden, 2011); off sourcing success (Ang \& Inkpen, 2008); CQ and firm international ties (Charoensukmongkol, 2015); cultural intelligence and export performance (Charoensukmongkol, 2016); cultural intelligence and conflict managemnt styles (Gonçalves, Reis, Sousa, Santos, Orgambidez-Ramos, \& Scott, 2016), cultural intelligence and organisational agility (Teimouri, Ardestani, \& Kheiri, 2016) and in 
Mediating role of cultural intelligence between relational governance and firm social performance

Pakistan perspective cultural intelligence has insignificant relation with managerial effectiveness (Aslam, Ilyas, Imran, \& Rahman, 2016).

There is limited evidence regading the contribution of cultural intelligene to the firm performance.In particular, there is need to integrate the concept of CQ at the firm level to the organizational outcomes,this remains under researched (Ang \& Inkpen, 2008). We propose that firm cultural intelligence will facilitate the development of joint planing initiative at stages of interaction with other partners and also help to resolve problesm occurs due to cultural difference. CQ is one form of cultural competence, defined as "the ability to function effectively in another culture or in a culturally diverse setting, and is essential for firm as it facilitates understanding, adaptation, communication, and coordination in diverse settings" (Johnson, Lenartowicz, \& Apud, 2006). To address this gap in research, the present study is examine CQ as a firm cultural capability for the management of relationship with their foreign counter parts.

The aim of this research is to develop better understanding of how cultural intelligence capabilities acquire knowledge resources from partner firm and utilize it to enhance firm social performance. The research question for this study is proposed, to what extent does cultural intelligence mediates the effects between supplier informal relationship mechanism with customers and firm social performance.

This study made two important contributions to the governance literature in international business. First, this study is first to test cultural intelligence capability mediate the effects on the relationship between cooperative norms and joint planning initiatives and improve firm social performance in developing country manufacturing perspective. Findings suggest that CQ is a knowledge acquisition capability which helps to preserve the relationship between the partners on social issues. Second, CQ capability is recurrently discussed in organizational behavior literature, this study provides evidence over the cultural intelligence in strengthens cooperative behavior. The remainder of this paper is structured as follows: In the following section, a brief review is provided of social exchange theory and resource base view.Next, based on this foundation a conceptual frame work is presented and drive research hypothesis. Next, research methodology is explained with regard to data collection and operationaliation of construct,followed by result analysis and then discuss the results findings.Finally, discuss managerial implications, limitations and provide future research direction.

\section{Literature Review}

\subsection{Theoretical View}

The social exchange theory (SET) is a theoretical lens for relational governance mechanism. In the relational governance mechanism, resources of the firm become more valuable as a result of employees exchange of information coordination and the employees likely to perform the compliance. Metacognitive CQ is knowledge and control of cognition, the processes individual use to understand knowledge and acquire, cognitive facets of CQ deal with information processing aspects of intelligence that are closely linked to individual learning processes in culturally diverse situations (Ang, Van Dyne, \& Koh, 2006). According to (Moon, 2010), closely related to the firm capability, such as cross-cultural coordination and integration process especially for cross-cultural learning process for combining appropriate procedures, practices and structures.

Motivation CQ acknowledges that most learning and developing intercultural competencies involves the inherent preference for interacting with people from different cultures, having confidence in culturally diverse interactions, and the management of stress from adjusting to unfamiliar settings (Ang, Van Dyne, Koh, $\mathrm{Ng}$, Templer, Tay, \& Chandrasekar, 2007).

The buyer-supplier relationship may be subject to the justice perception derived from social interaction and communication (Liu, Huang, Luo, \& Zhao, 2012). Social exchange theory focus on the roles of social interactions, it govern exchange relationship between the parties because it generate standard of expectations and 
Awan, U., \& Kraslawski, A.

discoursing malfeasance and opportunism (Granovetter, 1985). This study argue that, all these actions taken by the supplier firm likely to give compliance to the buyer firm with the purpose of gain knowledge sharing (Narasimhan, Nair, Griffith, Arlbjørn, \& Bendoly, 2009). According to (Cook, Cheshire, Rice, \& Nakagawa, 2013) social relationships deriving primarily upon ties of mutual dependence relationship. behavioral CQ refers to individual capability to display adequate verbal and nonverbal actions in cross-cultural context (Ang et al., 2006). Social exchange theory is used to gain understanding of buyer supplier relationship (Narasimhan et al., 2009).

According to resource based theory, resources refers to the tangible and intangible assets a firm used to select and implement its strategies, whereas capabilities is defined as a firm's capacity to deploy resources (Barney, 1991). The resource-based theory, views firms as composing of a set of resources and capabilities and firm performance is determined by the amount of capabilities and resources a firm has (Barney \& Felin, 2013). Here, applying RBV, we argue that adaptation and exert efforts for learning requires ones having capability needed for a given learning. The effectiveness of CQ capability to adapt or acquire behaviors appropriate for culture adjustments (Earley, 2002).

According to the RBV, individuals interact and learn new skills for development of capability. process capability of organizational CQ refers to "organizational capability when integrating and coordinating a firm's routine or pattern of practices, continuously creating bundles of new resources and knowledge, and restructuring and transforming resources in cross-cultural environments" (Moon, 2010). Resources and competencies provide competitive advantage, when they are adequately managed in cross cultural coordination. This firm capability reflects the knowledge acquisition capability, integrating and transform to enhance the performance. A firm's capability is embedded in distinct ways of coordination (Teece \& Pisano, 2004). Since the CQ is special firm routine for coordination and interaction for collecting and processing information. The knowledge a firm acquire during cross-cultural interaction is become rare assets. As such, the RBV take perspective that acquires new skills for adaption becomes the assets. The successful management of stakeholder pressure may led to offer more learning, build capability and impact on social performance (Awan, 2017). Relational ties with the stakeholders may help firm to build unique rare and imitable knowledge resources.

\subsection{Informal Relationship Mechanism and Social Performance}

According to Poppo and Zenger (2002), informal or relational governance, the enforcement of promise, obligations, expectations through social process that promote norms of flexibility (facilitate adaptations), solidarity (promotes a bilateral approach to problem solving) and information sharing (creating a commitment to joint communication and adaptations because partners are willing to share all information's).

Inter-organizational relationship between the firms are important to achieve the competitive advantage in supply chain management (Lumineau, 2015). As it highlighted in the literature informal relational mechanism explain the performance (Cao \& Lumineau, 2015). A recent research findings of (Arikan, Kantur, Maden, \& Telci, 2016) support the argument reputation plays a key role in shaping the behavioral intentions of prospective customers. Informal relational mechanism provide a framework of reference and guide firms to act in expected ways (Liu et al., 2009).

For example, in the context of the present study, a supplier work to the customer (buying firm) on informal contracts, such as cooperation and exchange of information. In this process, firm employees interact with the customer firms, acquires the skills necessary to carry out the relationship build capabilities, which ultimate transform to a are assets. In the context with the informal relational mechanism, prior researchers Gulati and Nickerson (2008) and Nyaga, Whipple, and Lynch (2010) assessed it with the social exchange theory. Social Exchange theory take the perspective in gaining rewards (Bandura 1986). "For example, in the context of the present study, a supplier firm makes informal relational mechanism with the buyer. The both partner frequently exchange of information, shared knowledge and enhance cooperation with the motivation to improve social 
performance. Besides, academic research literature has established economic, environmental and social performance is interrelated with each other (Cruz \& Matsypura, 2009).

More importantly, developing joint planning shift the focus away from self-centered behavior and allow two partners to design their business process for better coordination between them (Cai et al., 2009).This form of cooperation may influences participants, as they learn from each other culture specific conditions on social issues, work together and begin to invest in relationship specific investment. Inter-organizational relationship between the firms are important to acquire knowledge resources and achieve the competitive advantage (Lumineau \& Henderson, 2012). As an informal relational mechanism, joint problem solving allow partners to propose specific patterns to work on dispute resolution strategies (Claro, Hagelaar, \& Omta, 2003). The settlement of dispute effectively may allow to partners to share knowledge and resources that are necessary to implement the social practices. The successful integration of knowledge and resources will help to enhance social performance. According to (Mohr, Fisher, \& Nevin, 1996), Collaborative communication between two parties allows them to access relevant information as in the case of hierarchy. It allows them to effectively coordinate and facilitate resource sharing (Sirmon, Hitt, \& Ireland, 2007). Consequently, it promotes knowledge transfer, allowing partners to learn from each other, lead to complete task more effectively (Liu et al., 2009; Mohr et al., 1996). Such collaboration is critical to the performance in the firm. Business organizations cannot operate successfully without the cooperation of the society in which it is located (Akinyomi, 2013).

Some research scholars refer and connect social sustainability with the sustainable management of social resources, such as, people abilities, skill and social values (Sarkis, Zhu, \& Lai, 2011). Previous research has demonstrated, sharing resources and knowledge to firm supplier lead to improve social performance (Beske, Koplin, \& Seuring, 2008; Klassen \& Vereecke, 2012). Social performance aspects in the manufacturing firm are of particular concern in the improvement of safety issue, child labor, health, living conditions and equity problems (Hutchins \& Sutherland, 2008). Although, researchers highlighted establishing effective measures and process for social performance (Carter \& Rogers, 2008; Klassen \& Vereecke, 2012; Sancha, Gimenez, \& Sierra, 2016). Thus, informal relational governance on social issues could result in improved supplier performance.

$>$ H1: Relational governance is positively associated to the firm social performance

\subsection{Cultural Intelligence}

Earley and Ang (2003) conceptualized CQ as a multi-faceted characteristic consisting of meta-cognitive, cognitive, motivational and behavioral components. Meta-cognitive CQ is defined as the extent to which an individual's level of cultural awareness and mindfulness use to acquire and understand knowledge. Sternberg framework is noteworthy because it propose intelligence as having different loci within the person meta-cognition, cognition and motivate and mental capabilities. CQ defined as a person's capability to successfully adapt to new cultural settings (Earley \& Ang, 2003) is likely a more powerful mediator . Individual possess of MCQ would observe the situation and think about what is appropriate before speaking (Duff et al. 2012). This implies that the people with high MCQ is speak less but in accordance to the situation. With these capabilities, it promotes individual to act according to the situation. More specifically, motivational CQ are critical to real world problem solving. Auditing, code of conduct and standards that are initially present by a firm. Hence, global managers that are knowledgeable of and able to understand and adjust to cultural differences might develop a more positive attitude (Barakat, Lorenz, Ramsey, \& Cretoiu, 2015).

Cognitive CQ refers to an individual knowledge norm, conventions and practices acquire as well as knowledge of cultural differences (Ang \& Inkpen 2008). Cognition (CQ) is a competence based individual knowledge ability of cultural environments, including legal, economic and social system of different cultures as well as the norms and values of these cultures (Ang et al., 2007). It refers to one's knowledge about the similarities and differences about the structures of a culture (Livermore, 2011; Ng, Van Dyne, Ang, \& Ryan, 2012). This is important layer of CQ which reflects person capability to understand cultural differences in 
business practices and increased individual preferences for avoiding conflicts and increase cooperation to achieve an outcome. Cultural norms on social issues are varying with culture and each country take different approach to solve the problem. In this regard, individuals with metacognitive CQ tend to be mindful of their cultural knowledge before and during intercultural interactions (Thomas, Elron, Stahl, Ekelund, Ravlin, Cerdin, et al. 2008). For example, when supplier firm is knowledgeable about foreign partner culture, they tend to be more effective in identifying key issues that drive performance outcomes (Nadkarni, Herrmann, \& Perez, 2011). Motivational CQ refers to an individual's ability to direct attention and energy toward adapting and functioning in culturally diverse situation (Ang et al., 2007). Motivational CQ is critical component; it triggers effort and directed toward functioning in novel culture. More specifically, this dimension encompasses both intrinsic and extrinsic, as well as individual's confidence. CQ-Behavior refers to the individual ability to display the appropriate verbal and non-verbal behavior during interactions in a range of cross cultural situations (Ang et al., 2007; Earley \& Ang, 2003), these characteristics reflects a willingness to adapt and adjust to the specific practices specify needs of foreign partner.

A number of previous studies lend empirical and theoretical support to the relationship between CQ, conflicts handling and relational ties. Dynamic capability view of the firm suggests that the way firm uses internal cultural intelligence capabilities to coordinate with external partner to acquire knowledge and combined with internal capabilities may determine performance outcomes. Considering the importance of cultural intelligence can enhance collaborative communication, joint planning initiates as well as acquire knowledge and resources. Thus, the following hypothesis is presented:

H2: Relational governance is positively associated to the cultural intelligence.

H3: Cultural Intelligence mediates the relationship between relational governance and firm social performance.

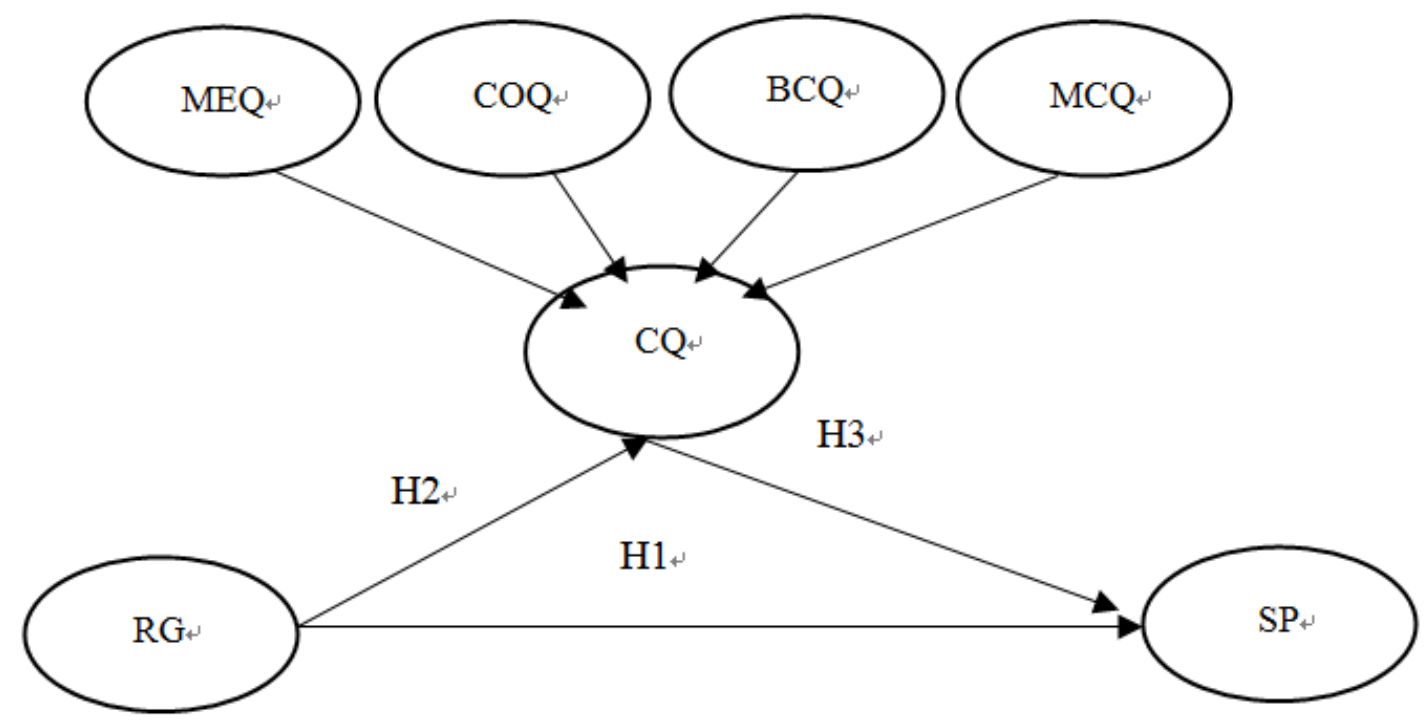

Figure 1. Theoretical Framework

Notes. RG: Relational governance, SP: Social Performance, CQ: Cultural Intelligence, MEQ: Meta Cognitive, COQ: Cognitive, BCQ: Behavior Cognitive, MCQ: Motivational culture Intelligence. 


\section{Research Design and Methodology}

\subsection{Measures}

All items and construct were adapted from previous studies and were measured by using a seven-point Likert scale. The items measures were largely grounded on the western literature, while data were collected in Pakistan. Prior to data collection, two pre-test were conducted. We used pilot test using 12 manufacturing firms in the Sialkot region. Four Academicians were professors in the field of international business and operations management from three universities. Based on the feedback received from the academicians and quantitative analysis, we reworded and modified a few to enhance clarity and refine survey instrument to appropriate adapt to the local context in Pakistan and removed five items from CQ scale. Based on the feedback, two items of relational governance were reworded and three items from the cultural intelligence scale. Pre-test improve the clarity of the questionnaire and ensured accurate, effective and unambiguous communication with the respondents. Relational governance scale was operationalize on the basis of the work by (Lusch \& Brown, 1996) and cultural intelligence by (Ang et al., 2007). Social performance to the firm was assessed on the basis of (Awaysheh \& Klassen, 2010; Kleindorfer, Singhal, \& Wassenhove, 2005). All constructs included in the structural model were measured using Likert scales drawn from prior studies and adapted to fit the context of the investigation. The adopted measures have been used in previous studies.

\subsection{Data collection and sampling issues}

This study defined its population as manufacturing firms that have production facilities and sell its products to foreign markets. This study used the exporter directory of textile firms, leather wares, sports goods and surgical instruments manufacturer as its sampling frame. Pakistan is an ideal setting to investigate business to business (B2B) relationship, given its status to largest supplier of sports goods, textile and surgical goods to many international buyers. Exporter firm respondents were asked to answer the questionnaire instrument with reference to the relationship with the specified importing buyer in mind.

Prior to data collection, two pre-test were conducted. First, 6 academicians were consulted, two were from the strategic management, two were from International business and two were from supply chain management field. This process is resulted the identification of concerns of few items that were not applicable or ambiguous, feedback resulted in the elimination of two items from behavioral cognitive "I vary the rate of my speaking when a cross cultural situation" and "I alter my facial expression when a cross culture interaction requires it". Three items from cognitive were eliminated "I know the rules (e.g., vocabulary, grammar) of other languages", "I know the marriage systems of other cultures" and "I know the arts and crafts of other countries".

Pre-test improve the clarity of the questionnaire and ensured accurate, effective and unambiguous communication with the respondents. In pre-test 1 , a brief questionnaire containing the items were given in person to operations managers with extensive export experience and were involved in dealing with international customers across different countries for at least 5 years. The managers were asked to point out any items that were both ambiguous and not related to their practices. This process is resulted the identification of concerns of two items that were not applicable or ambiguous, feedback resulted in the elimination of two items. Based on the feedback received from the academicians and quantitative analysis, we reworded and modified a few to enhance clarity and refine survey instrument to appropriate adapt to the local context in Pakistan and removed five items from CQ scale. Based on the feedback, two items of relational governance were reworded and three items from the cultural intelligence scale.

Data was collected by means of cross-sectional survey methodology. The sampling frame included 1652 export manufacturing firms operating in different industrial sector. To be eligible, the firm must have registered and involved in export business in the last 5 years. Data were obtained through a key informant design is 
Awan, U., \& Kraslawski, A.

common in studies of buyer supplier relations, which is consistent with earlier studies. Senior managers were selected as informants from different departments who were primarily responsible for the firms' international trade activities.

Table 1

Validation of constructs Survey items, item means, standard deviation

\begin{tabular}{|c|c|c|c|c|}
\hline Items & & $\begin{array}{c}\text { Factor } \\
\text { loadings a }\end{array}$ & Error Variance & Item $\mathrm{R}^{2}$ \\
\hline \multicolumn{5}{|c|}{ Relational Governance (IRG) AVE:0.649, $\alpha: 0.820$, CR: 0.880} \\
\hline & RG1 & 0.864 & 0.254 & 0.746 \\
\hline & RG2 & 0.805 & 0.352 & 0.648 \\
\hline & RG3 & 0.772 & 0.404 & 0.596 \\
\hline & RG4 & 0.778 & 0.395 & 0.605 \\
\hline \multicolumn{5}{|c|}{ Social Performance (SP) AVE:0.649, $\alpha: 0.819$, CR: 0.881} \\
\hline & SSP1 & 0.770 & 0.407 & 0.593 \\
\hline & SSP2 & 0.850 & 0.278 & 0.722 \\
\hline & SSP3 & 0.827 & 0.316 & 0.684 \\
\hline & SSP4 & 0.774 & 0.401 & 0.599 \\
\hline \multicolumn{5}{|c|}{ Cultural Intelligence (CQ) } \\
\hline \multicolumn{5}{|c|}{ Meta cognitive AVE:0.634, $\alpha: 0.720$, CR: 0.838} \\
\hline & MEC1 & 0.817 & 0.333 & 0.667 \\
\hline & MEC2 & 0.821 & 0.326 & 0.674 \\
\hline & MEC3 & 0.749 & 0.439 & 0.561 \\
\hline \multicolumn{5}{|c|}{ Cognitive AVE:0.656, $\alpha: 0.744$, CR: 0.851} \\
\hline & COQ1 & 0.730 & 0.467 & 0.533 \\
\hline & COQ2 & 0.871 & 0.241 & 0.759 \\
\hline & COQ3 & 0.823 & 0.323 & 0.677 \\
\hline \multicolumn{5}{|c|}{ Behavior Cognitive AVE:0.577, $\alpha: 0.759$, CR: 0.845} \\
\hline & BCQ1 & 0.769 & 0.409 & 0.591 \\
\hline & BCQ2 & 0.736 & 0.458 & 0.542 \\
\hline & BCQ3 & 0.776 & 0.398 & 0.602 \\
\hline & BCQ4 & 0.756 & 0.428 & 0.572 \\
\hline \multicolumn{5}{|c|}{ Motivational Cognitive AVE:0.602, $\alpha: 0.784$, CR: 0.858} \\
\hline & MCQ1 & 0.758 & 0.425 & 0.575 \\
\hline & MCQ2 & 0.782 & 0.388 & 0.612 \\
\hline & MCQ3 & 0.822 & 0.324 & 0.676 \\
\hline & MCQ4 & 0.740 & 0.452 & 0.548 \\
\hline
\end{tabular}

Notes. MCQ: Motivational culture Intelligence, MEC: Meta Cognitive Intelligence, BCQ: Behavior Cognitive, $\alpha$ : Cronbach's alpha

A randomized sample of 650 firms was selected out of a total of 1652 exhibiting manufacturer that have production facilities. In order to enhance response rate, the best practices for maximizing responses in a survey suggested by (Dillman, 2011) were followed. Each firm was contact by phone to solicit their cooperation in participating in this research study. Out of 650 firms, 316 firms that agreed to complete the questionnaire, a final total of 257 exporting firms fully completed questionnaires resulting in a response rate of 39.5\%. In all, 239 usable questionnaires were received, representing a response rate, which is consistent with results is reported in similar studies.

Non-response bias was assessed following (Armstrong \& Overton, 1977) guidelines, which has been used in the previous studies. The t-test performed on early respondents and late respondents yielded no statistically significant difference at $95 \%$ confidence interval. The results suggest that non-response bias does not pose to be a problem for this data set. Common method variance is poses a serious threat in behavioral research, particularly when data collected using single informants the interpretation of the data. Harmon's one factor test (Podsakoff, MacKenzie, Lee, \& Podsakoff, 2003) was carried out using an un-rotated factor analysis of all independent and dependent variables. The results revealed that a total of $71.2 \%$ of variance was accounted for that the first factor captured only $28.8 \%$ of the variance. This suggests that common method variance is not a significant problem in this study. 


\section{Data Analysis}

The unidimensionality of the dataset were assessed using principal component factor analysis. The assumption of unidimensionality met when all items in a scale measure a single construct (Dunn, Seaker, \& Waller, 1994). The unidimensionality of the data is perquisite before the before establishing overall construct reliability (Anderson \& Gerbing, 1988). The values of fit statistics, such as goodness of fit index (GFI) $>0.90$, comparative fit index (CFI) $>0.90$, the root mean square error of approximation (RMSEA) $<0.05$ (Anderson \& Gerbing, 1988). Cronbach's coefficient alpha and composite reliability is the most widely used measure to determine whether the scales are consistent and reliable (Anderson \& Gerbing, 1988).

Composite reliability was calculated using the procedures outlined by (Fornell \& Larcker, 1981). Garver and Mentzer (1999) also suggest that average variance extracted $>0.50$ and Cronbach's alpha value $>0.70$ indicate sufficient reliability. Hair, Black, Babin, and Anderson (2010) suggest that values of Bentler-Bonnett normed fit index (NFI) $>0.90$ of a scale demonstrate strong convergent validity. "Discriminant validity is the extent to which the measure is indeed novel and not simply a reflection of some other variable" (Churchill Jr., 1979). All items were loaded significantly on their respective factors. In addition to this, discriminant validity was assessed comparing square root of average variance extracted for each component is greater than the correlation between components; results provide strong evidence of scale reliability and discriminant validity. The testing results show that all construct were significantly different, indicating acceptable construct validity (see table.1). The final measurement results for the scales together with a correlation matrix are shown in Table 2.

\subsection{Empirically Tested of Hypothesized Model}

After making sure the construct validity and reliability of the data set were satisfied. The structural model in Figure 1 tested using AMOS v.23. A structural model with relational governance as exogenous latent variable, cultural intelligence as mediator and social performance as endogenous variable was construct in conceptual model (see Figure.1) and tested using covariance base structural equation modeling approach. The fit indices for overall model (see table.3), including CQ as higher order construct were as follows: chi square/degree of freedom ratio $[\mathrm{CMIN} / \mathrm{df}]=1.662$ Goodness of Fit indices $(\mathrm{GFI})=0.951$, root mean square error of approximation $($ RMSEA $)=0.044$, comparative fit index $(\mathrm{CFI})=0.950$, normed fit index $(\mathrm{NFI})=0.944$. The values of fit statistics exceeded the recommended benchmarks. The results of fit indices collectively indicate that structural model has a satisfactory acceptable fit. The structural model explains $47.8 \%$ of the variance in the social performance. The results support the hypothesis and in particular, confirm the full mediation of cultural intelligence $(\mathrm{CI})$. The results indicate that relational governance significantly and positively relates to firm social performance $(b=.244, \mathrm{t}=4.57 . \mathrm{SE}=0.053)$ providing support for the hypothesis. There is also a positive relationship between relational governance and cultural intelligence $(b=.161, t=5.509, S E=0.0029)$, supporting the hypothesis.

\section{Table 2}

Correlations and results of discriminant validity

\begin{tabular}{|c|c|c|c|c|c|c|}
\hline & $\mathrm{BCQ}$ & COQ & MCQ & MEC & $\mathrm{RG}$ & SP \\
\hline BCQ & .759 & & & & & \\
\hline COQ & $.125^{*}$ & .810 & & & & \\
\hline MCQ & $.188 * *$ & $.127 *$ & .776 & & & \\
\hline MEC & $.257 * *$ & $.205 * *$ & $.142 *$ & .195 & & \\
\hline RG & $.176^{* *}$ & $.190 * *$ & $.310 * *$ & $.195 * *$ & .805 & \\
\hline SP & $.355^{* *}$ & $.319 * *$ & $.227 * *$ & $.188 * *$ & $.295 * *$ & .806 \\
\hline
\end{tabular}




\section{Table 3}

Direct, and indirect effects of $R G$ on Social sustainability performance through Cultural Intelligence

\begin{tabular}{rcccccccc}
\hline \multicolumn{1}{c}{ Total effect $(c)$ : } & \multicolumn{3}{c}{ Direct effect $\left(c^{\prime}\right):$} & \multicolumn{2}{c}{ Indirect effect } \\
\hline Relationship & $\mathrm{b}$ & $\mathrm{t}$ & $\mathrm{SE}$ & $\mathrm{b}$ & $\mathrm{t}$ & $\mathrm{SE}$ & $\mathrm{b}$ & $\mathrm{SE}$ \\
IRG to SP & .244 & 4.57 & .053 & .142 & 2.71 & 0.052 & .101 & .0322 \\
LLCI & .1390 & & & .0389 & & & .0488 & \\
ULCI & .3492 & & & .2463 & & & .1764 &
\end{tabular}

${ }^{a}$ Sobel test results $\quad \mathrm{b}=0.103, \mathrm{SE}=0.0258, \mathrm{Z}=4.018, p=.001$

Note. Standardized results based on 5000 bootstrap samples in Hayes's (2013) PROCESS macro.

Bias-corrected $95 \%$ confidence interval reported in brackets. Indirect effects that are statistically significant are in bold.

$\mathrm{k}^{2}=$ Kappa-squared value. $\mathrm{k}^{2}=0.123, \mathrm{SE}=0.035$ (BootLLCI=0.0532, BootULCI=0.1909).

We also examined the mediating effect of cultural intelligence on the relationship between the RG and SP. To test mediation; we assessed the significance of the indirect and total effects of RG on SP. We followed the causal step approach in testing for mediation proposed by (Baron \& Kenny, 1986) and a bootstrap approach (Bollen, Lennox, \& Dahly, 2009).we examined mediation analysis via the PROCESS macro developed by (Preacher \& Hayes, 2008) in SPPS, using 95\% confidence interval (CI) with 5000 re-sample bootstrapping. We also report $\mathrm{K}^{2}$ statistics to provide a standardized effect size for any significant effects following recommendation for estimating " the proportion of the maximum possible indirect effect that could have occurred" (Preacher \& Kelley, 2011). The results (see table.3) show that CQ not only has a direct relationship with social performance but also mediates the relationship between CG and SP. The indirect effect of CG on SP through CQ is significant $(b=.101, \mathrm{SE}=0.032)$. The results of mediation analysis are presented in Table 3 . The direct effect of relational governance on social performance does not contain zero in the $95 \% \mathrm{CI}$, direct effect is not significant different from zero at $p<.05$, supporting CQ partially mediates the relationship between IRG and SP. The present results have shown that the social exchange perspective that views relational contracts in the form of norms or personal relation itself driver for inter firm trust, cooperation and information exchange, is an effective means of governance. Cooperation and information exchange behavior of supplier firm towards their buyer are motivated by rewarding trustworthy reactions.

\section{Conclusions}

The results provide insight into relevance of cultural intelligence for the social sustainability performance. We consider relational governance as joint planning and joint problem solving between the firms involved in exchange relationships. This study extends previous research on relational governance by providing a better understanding of how cultural intelligence capability of supplier firm enhances the informal relational governance in developing country. This study provides evidence that CQ capabilities are essential for acquisition of knowledge; firms are gained through jointly working and solving problem jointly. Findings confirm that cultural intelligence capabilities are required for maintaining effective buyer supplier relationship and improving firm social performance in Pakistan business context.

Cultural intelligence is consists of knowledge, thinking, motivation and behaviors and is an adaptive cultural capability (acquires knowledge, adaptive to knowledge and applies knowledge). In this study we argue that individuals equips with adapt and performance characteristics of cultural flexibility. We found that individual with CQ tend to have cooperative norms and enable them to overcome hurdles in joint planning and perform well in resolving conflicts through investing more cognitive efforts. Thus, CQ maintains more stable inter-firm relationship, help to acquire more knowledge on social issues, ultimately achieving more social sustainable outcomes.

Our study shows that CQ considerations are an important determinant of social performance and partially account for the joint planning and problem solving Therefore, it is necessary to consider CQ teams in joint working and problem solving, because having CQ helps to acquire more knowledge form partner, and apply it to achieve social performance outcomes. Overall, findings demonstrate that CQ is important for joint planning and 
problem solving and facilitates the processing of new knowledge, which supplier firm utilizes to enhance its social performance. The present of CQ provide no room for misunderstanding rather a cooperative norm is maintained in channel relation to facilitate information sharing and communication on social issues. The findings of this study indicated that CQ provides behavior flexibility, intrinsic interest and adaptability to acquire new in cross cultural setting, represent an important external learning and knowledge acquisition capability (Moon, 2010).Consistent with the previous research the four factors of CQ make unique contributions to effectiveness in culturally diverse settings (Ang, Rockstuhl, \& Tan, 2015). The CQ is associated with individual adaptive performance (Sahin \& Gürbüz, 2014), this implies that firm contains high level of CQ inclined towards high adaption to the partner requirements and utilize these adapted knowledge for improvement in social performance. The findings of this study provide a contribution and support the logic of organizational culture inevitable for the sustainable growth of firm (Awan, Muneer, \& Abbas, 2013). Cultural intelligence is not just about learning new cultural situations; it is creating "a new framework for understanding what he or she experiences and sees" (Earley \& Ang, 2003). It is suggested that cultural intelligence has the function of making individual a team oriented leadership and self-governance leaders.

The contribution of this study is to reveal the effectiveness of cultural intelligence clearly indicate that CQ lead supplier firm exhibited, a great influence on acquisition of knowledge is evident in joint planning and problem solving. It is suggested that, supplier CQ allow firm to more engage in joint planning and problem solving with partners, reduced uncertainty and more opportunities to enhance social performance. CQ establishes the basis for cooperative norms, such as joint planning and joint problem solving in order to function effective on social issue and make social performance sustainable. This study identified CQ as capability that improves informal relational governance, thereby outcomes. It is also worth considering the possibility that the CQ are best suited for avoiding conflicts, to help them do business more successfully in foreign markets and simultaneously improve social performance.

\subsection{Managerial Implications}

The findings provide managerial implications for top managers in export manufacturing firms. For managers, there are two important factors that contribute to enhance overall firm social performance. First, firm should accumulate the region specific cultural knowledge at the firm before embracing on the relationship with foreign partner by providing routine and structured training in terms of geographic specific cultural requirements. Second, they should have cultural intelligent employee. CQ is a behavior capability which can be developed with structured training programs. Management of firms needs to integrate cultural intelligence notion into management of buyer relationship in international export activities. For this, we propose that management of the firm should consider multicultural experience employees when uses relational contracts strategy with partner may enhance more trust, lead to develop credibility. Firms should rely on CQ capabilities to hand relational governance challenges to be expected with customers.

For buyer firm, manager advised to identify and prioritize the firm characteristics are conducive to support its way of doing relational contracts. It would be useful to identify those aspect of relational decision making that are critical for effectiveness of relational governance and then partner with those firms whose firm have employee experience in cross culture. We demonstrate that having CQ helps firm become more cooperative in global setting, and enhance more performance. For example, when working on a joint planning with foreign partner, managers with high CQ can use his cultural knowledge as a starting point to explore more ideas to effectively reach on decision. Managers should recognize the importance of informal relational governance elements, but also embraces elements of the cultural intelligence.

The research findings show that a retained cultural intelligence capabilities enables firms to better manage inter-firm relation (joint planning and problem solving).This suggest that retention of CQ capabilities allows firms to better recognize hazards in exchange relationships and make joint planning and problem solving for achieving sustainable social performance. It is suggested that the ability to adapt customer requirements is 
Awan, U., \& Kraslawski, A.

germane to managing the hazards of joint planning and problem solving. Finally, to attain social sustainability performance over the time, firms should ensure that retained team continuously focuses on development of CQ capabilities that can largely handle the relational governance.

\subsection{Limitations and future research guidelines}

The present study is obviously subject to some limitations that needed to be addressed, and offers promising future research areas that emerge from this study. Given the diversity of the social issues practices in different region and industries, social performance measure based on the perception of the respondents participated in the survey. Future research studies can rely on objective measures of social performance and interpreted with regard to the specific industries and regions. Future research is required to examine effect of the value of different kinds of contracting mechanisms and moderation role of cultural intelligence on relationship performance and organization citizenship behavior. The present study was restricted to relatively few exporting firms and their relationship with their foreign partners. A future research study is called for to replicate the study in other Asian country to demonstrate the generalizability of the findings in specific Asia cultural context. We evaluated the impact of four factors CQ to a firm's social sustainability performance, there are likely to be other capabilities which also can affect social sustainable performance outcomes and mediates the effect of relational governance. Future research is needed to identify cultural capabilities relevant to managing the relational governance activities. Ideally, future research should examine potential moderators of the relationship between relational governance and social performance are worthy of future examinations. For example, how emotional intelligence preferences are formed in exchange relationships, and the extent to which they are influenced by cultural differences between the partners.

\section{References}

Akinyomi, O. J. (2013). Survey of corporate social responsibility practices in Nigerian manufacturing sector. International Journal of Research Studies in Management, 2(1), 1-10. https://doi.org/10.5861/ijrsm.2012.177

Anderson, J. C., \& Gerbing, D. W. (1988). Structural equation modeling in practice: A review and recommended two-step approach. Psychological bulletin, 103(3), 411. https://doi.org/10.1037/0033-2909.103.3.411

Ang, S., \& Inkpen, A. C. (2008). Cultural intelligence and offshore outsourcing success: A framework of firm-level intercultural capability. Decision Sciences, 39(3), 337-358. https://doi.org/10.1111/j.1540-5915.2008.00195.x

Ang, S., Rockstuhl, T., \& Tan, M. L. (2015). Cultural intelligence and competencies. International encyclopedia of social and behavioral sciences, 2, 433-439. https://doi.org/10.1016/B978-0-08-097086-8.25050-2

Ang, S., Van Dyne, L., \& Koh, C. (2006). Personality correlates of the four-factor model of cultural intelligence. Group \& Organization Management, 31(1), 100-123. https://doi.org/10.1177/1059601105275267

Ang, S., Van Dyne, L., Koh, C., Ng, K. Y., Templer, K. J., Tay, C., \& Chandrasekar, N. A. (2007). Cultural intelligence: Its measurement and effects on cultural judgment and decision making, cultural adaptation and task performance. Management and organization review, 3(3), 335-371. https://doi.org/10.1111/j.1740-8784.2007.00082.x

Arikan, E., Kantur, D., Maden, C., \& Telci, E. E. (2016). Investigating the mediating role of corporate reputation on the relationship between corporate social responsibility and multiple stakeholder outcomes. Quality \& Quantity, 50(1), 129-149. https://doi.org/10.1007/s11135-014-0141-5

Armstrong, J. S., \& Overton, T. S. (1977). Estimating nonresponse bias in mail surveys. Journal of Marketing Research, 396-402. https://doi.org/10.2307/3150783

Aslam, U., Ilyas, M., Imran, M. K., \& Rahman, U. (2016). Intelligence and its impact on managerial effectiveness and career success (evidence from insurance sector of Pakistan). Journal of Management Development, 35(4), 505-516. https://doi.org/10.1108/JMD-10-2015-0153

Awan, U. (2017). Mediation analysis of environmental training: Perceived stakeholder pressure and 
Mediating role of cultural intelligence between relational governance and firm social performance

environmental supply chain management practices. International journal of Research Studies in Management, 6(1), 1-21.

Awan, U., Muneer, G., \& Abbas, W. (2013). Organizational collaborative culture as a source of managing innovation. World Applied Sciences Journal, 24(5), 582-587.

Awaysheh, A., \& Klassen, R. D. (2010). The impact of supply chain structure on the use of supplier socially responsible practices. International Journal of Operations \& Production Management, 30(12), 1246-1268. https://doi.org/10.1108/01443571011094253

Bandura, A. (1986). Social foundations of thought and action: A social cognitive theory. Prentice-Hall, Inc.

Barakat, L. L., Lorenz, M. P., Ramsey, J. R., \& Cretoiu, S. L. (2015). Global managers: An analysis of the impact of cultural intelligence on job satisfaction and performance. International Journal of Emerging Markets, 10(4), 781-800. https://doi.org/10.1108/IJoEM-01-2014-0011

Barney, J. (1991). Firm resources and sustained competitive advantage. Journal of Management. https://doi.org/10.1177/014920639101700108

Barney, J., \& Felin, T. (2013). What are microfoundations? The Academy of Management Perspectives, 27(2), 138-155. https://doi.org/10.5465/amp.2012.0107

Baron, R. M., \& Kenny, D. A. (1986). The moderator--mediator variable distinction in social psychological research: Conceptual, strategic, and statistical considerations. Journal of personality and social psychology, 51(6), 1173-1182. https://doi.org/10.1037/0022-3514.51.6.1173

Beske, P., Koplin, J., \& Seuring, S. (2008). The use of environmental and social standards by German first-tier suppliers of the volkswagen AG. Corporate Social Responsibility and Environmental Management, 15(2), 63-75. https://doi.org/10.1002/csr.136

Bollen, K. A., Lennox, R. D., \& Dahly, D. L. (2009). Practical application of the vanishing tetrad test for causal indicator measurement models: An example from health-related quality of life. Statistics in Medicine, 28(10), 1524-1536. https://doi.org/10.1002/sim.3560

Cai, S., Yang, Z., \& Hu, Z. (2009). Exploring the governance mechanisms of quasi-integration in buyer-supplier relationships. Journal of Business Research, 62(6), 660-666. https://doi.org/10.1016/j.jbusres.2008.02.004

Cao, Z., \& Lumineau, F. (2015). Revisiting the interplay between contractual and relational governance: A qualitative and meta-analytic investigation. Journal of Operations Management, 33, 15-42. https://doi.org/10.1016/j.jom.2014.09.009

Carter, C. R., \& Rogers, D. S. (2008). A framework of sustainable supply chain management: moving toward new theory. International journal of physical distribution \& logistics management, 38(5), 360-387. https://doi.org/10.1108/09600030810882816

Chandan, H. C. (2015). Impact of cultural intelligence on global business. Nationalism, Cultural Indoctrination, and Economic Prosperity in the Digital Age, 83. https://doi.org/10.4018/978-1-4666-7492-9.ch004

Charoensukmongkol, P. (2015). Cultural intelligence of entrepreneurs and international network ties: the case of small and medium manufacturing firms in Thailand. Management Research Review, 38(4), 421-436. https://doi.org/10.1108/MRR-09-2013-0214

Charoensukmongkol, P. (2016). Cultural intelligence and export performance of small and medium enterprises in Thailand: Mediating roles of organizational capabilities. International Small Business Journal, 34(1), 105-122. https://doi.org/10.1177/0266242614539364

Chen, X.-P., Liu, D., \& Portnoy, R. (2012). A multilevel investigation of motivational cultural intelligence, organizational diversity climate, and cultural sales: evidence from US real estate firms. Journal of applied psychology, 97(1), 93-106. https://doi.org/10.1037/a0024697

Churchill Jr., G. A. (1979). A paradigm for developing better measures of marketing constructs. Journal of Marketing Research, 16(1), 64-73. https://doi.org/10.2307/3150876

Claro, D. P., Hagelaar, G., \& Omta, O. (2003). The determinants of relational governance and performance: How to manage business relationships? Industrial Marketing Management, 32(8), 703-716. https://doi.org/10.1016/j.indmarman.2003.06.010

Cook, K. S., Cheshire, C., Rice, E. R. W., \& Nakagawa, S. (2013). Social exchange theory. In Handbook of 
social psychology (pp. 61-88). Springer. https://doi.org/10.1007/978-94-007-6772-0_3

Creque, C. A., \& Gooden, D. J. (2011). Cultural intelligence and global business competencies: A framework for organizational effectiveness in the global marketplace. International Journal of Management and Information Systems, 15(4), 141-146. https://doi.org/10.19030/ijmis.v15i4.5812

Cruz, J. M., \& Matsypura, D. (2009). Supply chain networks with corporate social responsibility through integrated environmental decision-making. International Journal of Production Research, 47(3), 621-648. https://doi.org/10.1080/00207540701513901

Dillman, D. A. (2011). Mail and Internet surveys: The tailored design method--2007 Update with new Internet, visual, and mixed-mode guide. John Wiley \& Sons.

Duff, A. J., Tahbaz, A., \& Chan, C. (2012). The interactive effect of cultural intelligence and openness on task performance. Research \& Practice in Human Resource Management, 20(1), 1-12.

Dunn, S. C., Seaker, R. F., \& Waller, M. A. (1994). Latent variables in business logistics research: scale development and validation. Journal of Business Logistics, 15(2), 145-172.

Earley, P. C. (2002). Redefining interactions across cultures and organizations: Moving forward with cultural intelligence. Research in organizational behavior, 24, 271-299. https://doi.org/10.1016/S0191-3085(02)24008-3

Earley, P. C., \& Ang, S. (2003). Cultural intelligence: Individual interactions across cultures. Stanford University Press.

Fornell, C., \& Larcker, D. F. (1981). Structural equation models with unobservable variables and measurement error: Algebra and statistics. Journal of Marketing Research, 18(13), 382-388. https://doi.org/10.2307/3150980

Garver, M. S., \& Mentzer, J. T. (1999). Logistics research methods: employing structural equation modeling to test for construct validity. Journal of business logistics, 20(1), 33-57.

Gonçalves, G., Reis, M., Sousa, C., Santos, J., Orgambidez-Ramos, A., \& Scott, P. (2016). Cultural intelligence and conflict management styles. International Journal of Organizational Analysis, 24(4), 725-742. https://doi.org/10.1108/IJOA-10-2015-0923

Granovetter, M. (1985). Economic action and social structure: The problem of embeddedness. American journal of sociology, 91(3), 481-510. https://doi.org/10.1086/228311

Groves, K. S., \& Feyerherm, A. E. (2011). Leader cultural intelligence in context: Testing the moderating effects of team cultural diversity on leader and team performance. Group \& Organization Management, 36(5), 535-566. https://doi.org/10.1177/1059601111415664

Gulati, R., \& Nickerson, J. A. (2008). Interorganizational Trust, Governance Choice, and Exchange Performance. Organization Science, 19(5), 688-708. https://doi.org/10.1287/orsc.1070.0345

Gunkel, M., Schlaegel, C., \& Taras, V. (2016). Cultural values, emotional intelligence, and conflict handling styles: A global study. Journal of World Business, 51(4), 568-585.

https://doi.org/10.1016/j.jwb.2016.02.001

Hair, J. F. J., Black, W. C., Babin, B. J., \& Anderson, R. E. (2010). Multivariate data analysis (7th ed.). Prentice Hall.

Hutchins, M. J., \& Sutherland, J. W. (2008). An exploration of measures of social sustainability and their application to supply chain decisions. Journal of Cleaner Production, 16(15), 1688-1698. https://doi.org/10.1016/j.jclepro.2008.06.001

Janssens, M., \& Brett, J. M. (2006). Cultural intelligence in global teams: A fusion model of collaboration. Group \& Organization Management, 31(1), 124-153. https://doi.org/10.1177/1059601105275268

Johnson, J. P., Lenartowicz, T., \& Apud, S. (2006). Cross-cultural competence in international business: Toward a definition and a model. Journal of international business studies, 37(4), 525-543. https://doi.org/10.1057/palgrave.jibs.8400205

Keung, E. K. (2011). What factors of cultural intelligence predict transformational leadership: A study of international school leaders. Liberty University.

Klassen, R. D., \& Vereecke, A. (2012). Social issues in supply chains: Capabilities link responsibility, risk (opportunity), and performance. International Journal of Production Economics, 140(1), 103-115. 
Mediating role of cultural intelligence between relational governance and firm social performance https://doi.org/10.1016/j.ijpe.2012.01.021

Kleindorfer, P. R., Singhal, K., \& Wassenhove, L. N. (2005). Sustainable operations management. Production and operations management, 14(4), 482-492. https://doi.org/10.1111/j.1937-5956.2005.tb00235.X

Liu, Y., Huang, Y., Luo, Y., \& Zhao, Y. (2012). How does justice matter in achieving buyer--supplier relationship performance? Journal of Operations Management, 30(5), 355-367. https://doi.org/10.1016/j.jom.2012.03.003

Liu, Y., Luo, Y., \& Liu, T. (2009). Governing buyer--supplier relationships through transactional and relational mechanisms: Evidence from China. Journal of Operations Management, 27(4), 294-309. ttps://doi.org/10.1016/j.jom.2008.09.004

Livermore, D. (2011). The cultural intelligence difference: Master the one skill you can't do without in today's global economy. AMACOM Div American Mgmt Assn.

Lumineau, F. (2015). How contracts influence trust and distrust. Journal of Management, 43(5), 1553-1577. https://doi.org/10.1177/0149206314556656

Lumineau, F., \& Henderson, J. E. (2012). The influence of relational experience and contractual governance on the negotiation strategy in buyer-supplier disputes. Journal of Operations Management, 30(5), 382-395. https://doi.org/10.1016/j.jom.2012.03.005

Lusch, R. F., \& Brown, J. R. (1996). Interdependency, contracting, and relational behavior in marketing channels. Journal of Marketing, 60(4), 19-38. https://doi.org/10.2307/1251899

Magnusson, P., Westjohn, S. A., Semenov, A. V, Randrianasolo, A. A., \& Zdravkovic, S. (2013). The role of cultural intelligence in marketing adaptation and export performance. Journal of Marketing Research, 21(4), 44-61. https://doi.org/10.1509/jim.13.0055

Mohr, J. J., Fisher, R. J., \& Nevin, J. R. (1996). Collaborative communication in interfirm relationships: moderating effects of integration and control. The Journal of Marketing, 160(3), 103-115. https://doi.org/10.2307/1251844

Moon, T. (2010). Organizational cultural intelligence: Dynamic capability perspective. Group \& Organization Management, 35(4), 456-493. https://doi.org/10.1177/1059601110378295

Nadkarni, S., Herrmann, P., \& Perez, P. D. (2011). Domestic mindsets and early international performance: The moderating effect of global industry conditions. Strategic Management Journal, 32(5), 510-531. https://doi.org/10.1002/smj.888

Narasimhan, R., Nair, A., Griffith, D. A., Arlbjørn, J. S., \& Bendoly, E. (2009). Lock-in situations in supply chains: A social exchange theoretic study of sourcing arrangements in buyer--supplier relationships. Journal of Operations Management, 27(5), 374-389. https://doi.org/10.1016/j.jom.2008.10.004

Ng, K.-Y., Van Dyne, L., Ang, S., \& Ryan, A. M. (2012). Cultural intelligence: A review, reflections, and recommendations for future research. Conducting multinational research: Applying organizational psychology in the workplace, 29-58. https://doi.org/10.1037/13743-002

Nyaga, G. N., Whipple, J. M., \& Lynch, D. F. (2010). Examining supply chain relationships: do buyer and supplier perspectives on collaborative relationships differ? Journal of Operations Management, 28(2), 101-114. https://doi.org/10.1016/j.jom.2009.07.005

Pagell, M., \& Wu, Z. (2009). Building a more complete theory of sustainable supply chain management using case studies of 10 exemplars. Journal of supply chain management, 45(2), 37-56. https://doi.org/10.1111/j.1745-493X.2009.03162.X

Podsakoff, P. M., MacKenzie, S. B., Lee, J.-Y., \& Podsakoff, N. P. (2003). Common method biases in behavioral research: a critical review of the literature and recommended remedies. Journal of Applied Psychology, 88(5), 879-903. https://doi.org/10.1037/0021-9010.88.5.879

Poppo, L., \& Zenger, T. (2002). Do formal contracts and relational governance function as substitutes or complements? Strategic Management Journal, 23(8), 707-725. https://doi.org/10.1002/smj.249

Preacher, K. J., \& Hayes, A. F. (2008). Asymptotic and resampling strategies for assessing and comparing indirect effects in multiple mediator models. Behavior research methods, 40(3), 879-891. https://doi.org/10.3758/BRM.40.3.879

Preacher, K. J., \& Kelley, K. (2011). Effect size measures for mediation models: quantitative strategies for 
Awan, U., \& Kraslawski, A.

communicating indirect effects. Psychological methods, 16(2), 93-115. https://doi.org/10.1037/a0022658

Sahin, F., \& Gürbüz, S. (2014). Cultural intelligence as a predictor of individuals' adaptive performance: A study in a multicultural environment. International Area Studies Review, 17(4), 394-413. https://doi.org/10.1177/2233865914550727

Sancha, C., Gimenez, C., \& Sierra, V. (2016). Achieving a socially responsible supply chain through assessment and collaboration. Journal of Cleaner Production, 112, 1934-1947. https://doi.org/10.1016/j.jclepro.2015.04.137

Sarkis, J., Zhu, Q., \& Lai, K. H. (2011). An organizational theoretic review of green supply chain management literature. International Journal of Production Economics, 130(1), 1-15. https://doi.org/10.1016/j.ijpe.2010.11.010

Sirmon, D. G., Hitt, M. A., \& Ireland, R. D. (2007). Managing firm resources in dynamic environments to create value: Looking inside the black box. Academy of management review, 32(1), 273-292. https://doi.org/10.5465/AMR.2007.23466005

Teece, D., \& Pisano, G. (2004). The dynamic capabilities of firms. Handbook on Knowledge Management, 3, 195-213. https://doi.org/10.1093/icc/3.3.537-a

Teimouri, H., Ardestani, M. M. B., \& Kheiri, A. (2016). Studying the relationship between managers' cultural intelligence and organisational agility (case of: selected branches of Bank Melli in Isfahan province, Iran). International Journal of Applied Management Science, 8(4), 338-353. https://doi.org/10.1504/IJAMS.2016.080330

Thomas, D. C., Elron, E., Stahl, G., Ekelund, B. Z., Ravlin, E. C., Cerdin, J.-L., et al. (2008). Cultural intelligence: Domain and assessment. International Journal of Cross Cultural Management, 8(2), 123-143. https://doi.org/10.1177/1470595808091787

Thomas, D. C., Liao, Y., Aycan, Z., Cerdin, J.-L., Pekerti, A. A., Ravlin, E. C., et al. (2015). Cultural intelligence: A theory-based, short form measure. Journal of International Business Studies, 46(9), 1099-1118. https://doi.org/10.1057/jibs.2014.67

Tuan, L. T. (2016). From cultural intelligence to supply chain performance. The International Journal of Logistics Management, 27(1), 95-121. https://doi.org/10.1108/IJLM-01-2014-0009 